Reseñas y notas 



\section{El impulso erótico y la ética}

\section{Luis Villoro}

Juliana González, El poder de eros. México-Buenos Aires-Barcelona, Paidós, 2000.

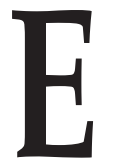

n 1986, Juliana González publicó un libro lúcido y atormentado: $E l$ malestar en la moral. Es una interpretación de la doctrina de Freud en la que discute su concepción del eros y su idea de la moral. Yo estaba en ese momento en el extranjero y no resistí mi deseo de expresarle a Juliana, en una carta, mi entusiasmo por su trabajo y mi esperanza de que prosiguiera la tarea que había apuntado en su libro: frente a la moral represiva, abrir una vía a una nueva ética que partiera del impulso erótico. Al recordar ese episodio no puedo menos que alegrarme de ver que, en este nuevo libro, empieza a cumplirse mi esperanza.

El poder de eros es un libro variado. Contiene ensayos que, aunque ligados entre sí por una preocupación intelectual común, tratan de asuntos diversos. Yo me detendré sólo en los que desarrollan aquella propuesta de Juliana de hace quince años: la relación entre el impulso erótico y la ética.

Juliana examina los distintos sentidos que presenta el concepto de eros en el pensamiento griego. Para nuestro tema, lo más fructífero de su análisis, me parece, es la importancia que le concede al mito narrado por Aristófanes, en el Banquete de Platón. Los seres humanos constituían una unidad que fue escindida a la mitad; a cada hombre o mujer le falta la entidad que le fue cortada; es pues un ser mutilado, carente. El amor es el impulso por recobrar nuestra unidad originaria, es el anhelo de restablecer nuestra integridad perdida. El eros, por lo tanto, al ser apetito de lo otro que nos falta, no es enajenación de sí, sino encuentro consigo mismo. (Cf. pp. 67-68).

Ese mito expresaría simbólicamente una característica de la naturaleza humana: "el hecho de que el hombre constitutiva y ontológicamente -escribe Juliana- está en relación con el otro”. El símbolo de eros expresa también que lo originario, el primer momento, es la unidad, la hermandad ontológica, la comunidad y la comunicación entre los seres humanos" (p. 69). Paradoja: ser plenamente uno mismo es "ser con los otros". 
El eros supone en el amante una carencia, una falta fundamental o -como diría Sartre, siguiendo a Husserl- una ausencia. ${ }^{1}$ Es, pues, hijo de penia. Pero, por experimentar una ausencia, es también tensión hacia aquello que aliviaría la falta. Por eso Juliana tiene razón en recordar, con Platón, que eros es también hijo de poros, término que sugiere plenitud y riqueza. Pero no creo que este segundo concepto añada algo al primero, como parece desprenderse de lo que dice Juliana (p. 66). Creo que es la otra cara de la noción misma de carencia. Porque la vivencia del deseo es la carencia que origina una insoportable tensión necesitada de alivio. Poros quiere decir vía, camino; y el camino implica que la meta está aún distante; es pues esa tensión por alcanzar algo ausente. Con otra terminología, podríamos decir que el eros es una actitud positiva, dirigida emotivamente hacia un valor del que se carece. Valor es lo que trasciende esa actitud, cargada de emoción, cuya realización satisfacería el deseo y colmaría la carencia. Por eso, eros se simboliza, como recuerda Juliana, por un ser alado, en perpetuo vuelo hacia lo otro, justamente aquello que no tiene.

Juliana advierte la ambivalencia del concepto de eros, su "naturaleza contradictoria" (p. 94). Desde un punto de vista que intenta ver su relación con la moral, el eros aparecería tanto como un principio de bien como de mal (p. 72). Por una parte, un erotismo "terrenal" implica dominación y tiranía sobre el alma, sujeción de ésta al poder de lo sensible. Por otra parte, el erotismo es elevación de lo terrenal hacia lo espiritual y de la apariencia sensible a lo real. Leyendo a Platón, concluye Juliana que en la naturaleza del eros habría "un conflicto e incluso un dualismo" (p. 74).

Este dualismo del eros podría dar lugar, en relación con el comportamiento moral, a un eros "malo" frente a uno "bueno". Juliana señala una diferencia entre "erotismo" y "amor". El primero "desprendido de todo compromiso moral, y por tanto de toda ley y medida, [...] tiende a la transgresión y la hybris". Ya en un artículo anterior había señalado cómo el deseo puro es "fuerza de hybris, de desmesura y violencia". ${ }^{2}$ Lo interesante de su posición es que sostiene ahora que "el propio erotismo, en cuanto erotismo, puede ser la fuerza vital en ascenso" (p. 79).

¿Cómo conciliar entonces esos dos aspectos del impulso erótico, el erotismo y el amor, cuya dirección - como en los dos caballos del carro de Platónes opuesta, pues el uno hala hacia la tierra mientras el otro obedece a la rienda del auriga? ¿Cómo podría el erotismo, fuerza de violencia, conjugarse con el amor, impulso de elevación? ¿Acaso el dualismo del eros terrenal y del espiritual podría superarse?

${ }^{1}$ Jean-Paul Sartre, L'etre et le néant, parte III, cap. 1.

2 Juliana González, "El sujeto moral en la ética griega", en Crítica del sujeto. México, UNAM, 1990, p. 23. 
Creo que ése es un problema central del libro y creo también que su principal mérito está en ofrecer una vía para intentar resolverlo. El eros, recordemos, nace de la vivencia de una carencia y del afán de unificación con aquello que nos falta. En esa característica deberíamos encontrar, por lo tanto, la diferencia entre el impulso que rebaja y el impulso que eleva. Ambos obedecerían al mismo anhelo por unirse con aquello que nos falta, pero su modo de intentarlo sería diferente. En este punto encontramos, a mi juicio, el principal acierto del análisis que realiza Juliana.

La supresión de la escisión del propio ser, que se vive como carencia, puede lograrse por la afirmación del otro, de lo otro, como alteridad que nos complementa. Pero puede intentarse también por el dominio o la aniquilación del otro. En este segundo caso el eros tiene la misma pretensión: suprimir la escisión reduciendo lo otro a uno mismo, pero quiere hacerlo al consumirlo o dominarlo (p. 84). Así las dos manifestaciones del eros intentan lo mismo de maneras opuestas. La primera logra su objeto donde fracasa la segunda.

Esta interpretación de la doble labor del eros presupone dos cosas: en primer lugar, tenemos que admitir dos dimensiones del yo: el yo limitado y carente, mutilado del otro, de lo otro, y el yo integrado, el "sí mismo", la persona cabal que verdaderamente nos constituye, la que podemos restaurar al romper nuestro estado carente. Lo cual quiere decir, en segundo lugar, que en la unión amorosa no alteramos nuestro yo, sino, por el contrario, lo encontramos. Platón escribió esta frase extraordinaria: Quien se duele por sentirse perdido en el amor -dice- "no se da cuenta que en su amante, como en un espejo, es él mismo el que se mira" ${ }^{3}$ Y Juliana: "El yo que niega al otro y ruega a la comunidad se niega en el fondo a sí mismo" (p. 125). En efecto, el designio del amor es realizarse a sí mismo por la afirmación del otro, de lo otro. ${ }^{4}$

Llegamos así al propósito más ambicioso del libro: lograr una ética que, lejos de oponerse, se funde en el eros. Es aquí, en mi opinión, donde el discurso se vuelve menos claro. "Ethos es creación de eros", nos dice Juliana. Debo suponer que no se refiere a todas las manifestaciones del eros, puesto que el erotismo que conduce a la dominación o a la destrucción del otro lleva, según el análisis de la propia Juliana, a la desmesura. Debemos entender que sólo puede ser una vía hacia la ética la otra forma de eros, la que consiste en una afirmación del otro, de lo otro, y por lo tanto en una realización de nuestro yo integrado. Pero entonces ęcómo distinguir claramente cuándo la fuerza del erotismo o del amor conduce a un comportamiento que pueda calificarse de ética, y cuándo no? ¿Qué criterio podemos tener para distinguir el eros de

\footnotetext{
3 Platón, Fedro, 255d.

${ }^{4}$ Luis Villoro, El poder y el valor. México, FCE, 1997, p. 381.
} 
transgresión y desmesura, que no conduce a una ética, y el que impulsa a la realización de sí mismo?

Admito que una forma de eros sería un impulso para una vida ética, como sostiene Juliana. En otra terminología, podríamos decir que la motivación para elegir una vida ética reside en una actitud emotiva, favorable a la realización de un valor objetivo, que se manifiesta como deseo o amor (eros). Pero para fundamentar los principios de un comportamiento ético ese impulso no basta. Necesitamos un criterio que nos permita distinguir cuándo ese impulso conduce a una vida auténtica y plena y cuándo nos encierra en nuestro yo carente. ¿Quién puede darnos ese criterio? Volvamos a Platón: ya no es la fuerza de los caballos, sino el juicio del auriga. Juliana, por supuesto, lo sabe. "La tendencia erótica al valor, la posibilidad de movimiento ascensional -escribe- es inconcebible también sin el concurso [...] de la razón, simbolizada por el auriga o cochero del carruaje alado del mito platónico" (p. 93). Pero entonces debemos entender que la ética no es "creación del eros" sino de la razón motivada por una forma de eros. Tenemos que distinguir por lo tanto, entre las razones objetivas que justifican un juicio moral y los motivos subjetivos por los que se formula.

Pero ¿de qué razón se trata? Porque los ejercicios de la razón son varios. No podría tratarse de una razón instrumental, es decir, de aquel uso de la razón que responde al interés exclusivo del sujeto en obtener para sí el máximo beneficio, sin preocuparse del interés del otro. Si la forma de eros que motiva una vida ética es la que intenta la realización del sujeto por la afirmación del otro, entonces la razón que justifica esa vida tiene que ser la que descubre los valores intersubjetivos que el otro puede aceptar como suyos. La labor del "auriga" consiste en discriminar lo deseado por un sujeto de lo objetivamente deseable.

Volvamos a nuestro tema inicial: la relación entre el impulso erótico y los principios éticos. Éstos no pueden derivarse del eros. Intentar hacerlo sería volver a una moral basada en tendencias emotivas o en deseos subjetivos, lo cual es, en realidad, una manera de negar la existencia de un orden moral. Pero un problema tradicional de la ética ha sido el de la motivación moral. ¿Por qué motivo habríamos de seguir dictados morales que, a menudo, van en contra de nuestros deseos individuales? ¿Qué nos movería a obedecer a principios racionales universales, si causan daño a nuestro impulso personal al goce? Y es en este punto donde el análisis de las distintas manifestaciones del eros podría indicarnos una respuesta. El motivo que nos impulsa a una vida ética no sería la sumisión a la autoridad o el miedo al castigo, pero tampoco un vago e intelectual "respeto a la ley". Lo que nos movería a la vida moral sería un impulso erótico inscrito en el fondo de todo hombre y de toda mujer: el anhelo de aliviar nuestra condición escindida y carente y de recuperar un 
ser personal integrado. La ética respondería así a una deliberación racional que trata de satisfacer una pasión, pero no la pasión por consumir y dominar el mundo para alimentar nuestro goce individual, sino otra pasión más profunda y permanente: la de realizarnos a nosotros mismos al unirnos con los otros, con lo otro, en un goce compartido.

La razón no tendría entonces por función ponerle límites al eros sino regular sus movimientos desordenados para que cumpla su verdadera misión: descubrir nuestro rostro auténtico al través de su espejo. 